\title{
3-DIMENSIONAL PRESERVATION OF INSECTS - PHOSPHATIZATION IN THE MIOCENE OF RIVERSLEIGH (QUEENSLAND, AUSTRALIA
}

DUNCAN*, Ian J. \& BRIGGS, Derek E.G., Department of Geology, University of Bristol, Wills Memorial Building, Queen's Road, Bristol, BS8 1RJ, UK.

The Tertiary limestones of Riversleigh (North Queensland) yield a diverse and well preserved terrestrial fauna. The marsupials from this site have trebled the mammalian record of the Australian continent. The recent discovery of insects (Coleoptera, Diptera) and rare myriapods from the Upper Site (Late Oligocene/ Early Miocene) has increased the taxonomic importance of the locality (Tertiary insects are rare in Australia), and provided an example of 3-dimensional phosphatization of arthropods in a terrestrial environment. This type of insect preservation is now recognized in a number of localities, e.g. Quercy Phosphorites (France), St Andrews cave deposits (Jamaica).

The Riversleigh insects preserve features of the cuticle at a resolution of microns. Details of setae, pores, and arthrodial membrane are evident, the internal structure of the cuticle including micro-layers and helicoidal pore canals is preserved, and fragments of phosphatized soft tissue remain within the carcass. Phosphatization also preserves features of the eye including the cornea and the emplacement of the rhabdom.

The insects preserve evidence of the organisms that initiated decay prior to mineralization. The hollow interior of a number of specimens is criss-crossed by strands of fungal hyphae and fungal growths also occur on the cuticle surface. Mineralized bacteria are found within the ommatidia of the compound eye of a number of specimens. The disarticulation sequence can be mimicked in laboratory experiments, providing an indication of the timing decay inhibition and diagenetic mineralization.

The Riversleigh fossils were deposited in a shallow lime-rich pool of limited extent in a tropical rain forest. Evaporation resulted in the formation of a salt crust on the surface of the pool which would have given the misleading appearance of a firm surface. Animals venturing onto the crust may have fallen through, resulting in the high concentration of vertebrate fossils. Scavengers were inhibited by the high salinity. The microbial mats which grew in the pool may have further enhanced the conditions of exceptional preservation (Archer et al 1989). The insects themselves are interpreted as scavengers which fed on the vertebrate carcasses [Supported by NERC studentship GT4/94/118/G.]

ARCHER, M., GODTHELP, H., HAND S.J., AND MEGIRIAN, D. 1989. Fossil mammals of Riversleigh, Northwestern Queensland: Preliminary overview of biostratigraphy, correlation and environmental change. Australian Zoologist, 25(2): 29-65. 